\title{
ANALISA KISAH YUSUF DALAM ALQURAN DENGAN PENDEKATAN HERMENEUTIKA
}

\author{
Dadang Darmawan \\ Dosen Fakultas Ushuluddin UIN Sunan Gunung Djati Bandung \\ Jl. A.H. Nasution 105 Cibiru, Bandung 40614, Indonesia. \\ E-mail: dadangdarmawan76@gmail.com
}

\begin{abstract}
Abstrak
Alquran sebagai mu'jizat nabi Muhammad yang paling besar, yang diturunkan belasan abad yang lalu tidak akan lekang ditelan zaman. Kandungannya akan selalu dan senantiasa menemukan relevansinya dengan kehidupan umat manusia di masa yang akan datang, dalam setiap generasi maupun peradaban. Memahami kandungan Alquran dengan pendekatan hermeneutika pada dasarnya dapat membuka wawasan baru, serta menemukan pemahaman yang segar dan aplikatif. Sebagaimana pisau, hermeneutika dapat memberi manfaat, juga dapat mendatangkan madharat, bergantung kepada siapa yang menggunakannya, dan untuk kepentingan apa. Artikel ini berusaha untuk menganalisa kisah Yusuf dalam Alquran dengan pendekatan hermeneutik. Artikel ini menunjukkan bahwa dalam kisah Yusuf, rangkaian peristiwa yang dialaminya saling berkaitan antara satu dengan yang lain, ada suka dan duka. Kita dapat berkaca pada kisah Yusuf, boleh jadi kelelahan, kepedihan dan kemalangan yang mungkin kita alami saat ini ada kebaikan yang belum kita lihat, ada rencana Allah yang masih menjadi rahasia.
\end{abstract}

Kata Kunci:

Hermeneutika; Yusuf;pemahaman; fenomenologi; dinamika teks; dekonstruksi.

\begin{abstract}
Alquran is a divine sacred text revealed to the Prophet Muhammad in the seventh century of Arabia. Its message is always relevant over time and space as a guidance for the Muslim community. Understanding Quranic message using hermeneutical approach can build a new meaning that needed by Muslim community in the current situation. This article analyzes the story of Yusuf in the Quran by employing hermeneutical approach. This article shows that many events in Yusuf's life are interconnected to each other, be it was happy or unhappy moment. We can learn from this story that tiredness, sadness and misfortune that we experienced in our life there must be goodness in those time that we have not been captured, and God has put plan on it.
\end{abstract}

Keywords:

Hermeneutics; Yusuf; understanding; fenominology; text dynamics; fusion of horizon; deconstruction.

\section{A. PENDAHULUAN}

Kisah-kisah dalam Alquran adalah kisah yang telah dipilih untuk diabadikan.Kisah tersebut bukan kisah biasa, melainkan sebuah sejarah yang sarat makna dan pelajaran berharga.Umumnya, dalam pembukaan atau akhir setiap kisah tersebut Allah swt. menekankan pentingnya memetik hikmah maupun rahasia di balik kisah-kisah itu.

Kisah-kisah dalam Alquran didominasi oleh kisah para Nabi dan Rasul.Selain kisah para nabi, adapula kisah manusia biasa namun memiliki sejarah yang mencolok, baik dalam kesalehannya, ataupun kejahatannya.Seperti, kisah Maryam, Ali Imran, Luqman, atau
Firaun, Tsamud, Haman, Qarun, dan lainnya.Semuanya mengandung ibrah yang dalam untuk menjadi cermin bagi generasi sesudahnya.

Salah satu cara yang dapat digunakan dalam memahami dan mengungkap rahasia di balik setiap kisah itu adalah dengan pendekatan hermeneutika. Secara bahasa hermeneutika berasal dari bahasa Yunani hermeneuein yang berarti "menafsirkan", kata bendanya hermeneia yang berarti "penafsiran", dan hermeneutes yang berarti penafsir. Richad E. Palmer kemudian mendefinisikan hermeneutika sebagai "proses

${ }^{1}$ E. Sumaryono,Hermeneutik: Sebuah Metode Filsafat, (Yogyakarta: Kanisius, 1999), 23-24. 
mengubah ketidaktahuan menjadi mengerti" (the process of bringing to understanding) yang meliputi tiga hal yaitu: (1) to say (menyatakan), to explain (menjelaskan), dan to translate (menerjemahkan). ${ }^{2}$

Memahami kisah seseorang dengan pendekatan hermeneutika dapat menjadikan pembaca merasakan apa yang dirasakan tokohtokoh dalam cerita tersebut, bahkan pembaca dapat larut dalam kisah tersebut seakan-akan dia sendiri yang mengalami kisah tersebut. Menyelami kisah para nabi dapat membuat kita merasakan apa yang dirasakan, memahami setiap kejadian dan mendapatkan pelajaran dari kisah tersebut.

Ada beberapa tokoh yang memiliki peran dan pengaruh besar dalam mengembangkan hermenuetika. Tokoh-tokoh tersebut menurut catatan Palmer, Sumaryono, dan Schmidt di antaranya adalah: Friedrich Ernest Daniel Schleiermacher (1768 -1834), Wilhelm Dilthey (1833 -1911), Hans Georg Gadamer (1900 -2002), Jurgen Habermas (1929-2009), Paul Ricoeur (1913-2005), dan Jacques Derrida (1930), dan Martin Heidegger (18891976). ${ }^{3}$

\section{B. HASIL DAN PEMBAHASAN}

\section{Hermeneutika Schleiermacher}

Menurut Schleiermacher Hermeneutika adalah seni memahami teks.Dalam pandangannya, setiap teks memiliki dua sisi, yaitu sisi eksternal dan internal.Sisi eksternal berkaitan dengan makna gramatikal teks.Adapun sisi internal berhubungan dengan makna psikologis pengarang.Dalam hal inilah hermeneutika sebagai seni memahami mulai berperan. Melalui interprestasi psikologis sang penafsir menempatkan dirinya ke dalam dunia batin pengarang, sampai tahap ia mengerti dan berkata: "Oh pantas ia begitu, karena kalau

${ }^{2}$ Richard E. Palmer, Hermeneutics Interpretation Theory in Schleiermacher, Dilthey, Heidegger and Gadamer, (Northwestern University Press, 1969),13.

3 Dadang Darmawan, "Kajian Hermeneutika Terhadap Fenomena dan Teks Agama", Holistic alHadis Jurnal Studi Hadis, Keindonesiaan dan Integrasi keilmuan, Vol. 02, No. 2 (Januari-Juni 2016), 3-5. aku dalam keadaan seperti itu, pasti aku juga akan berkata atau berbuat hal yang sama". Jadi untuk memahami maksud pengarang kita naik banding pada pengalaman kita sendiri. ${ }^{4}$

Dalam kaitannya dengan kisah Yusuf as.hermeneutika Schleiermacher dapat ditemui pada peristiwa Zulaikhayang dicela wanitawanita Mesir atas perbuatannya. Menurut mereka, Zulaikha dianggap telah mempermalukan martabatnya sendiri ketika tergila-gila kepada pembantunya.Uniknya, Zulaikha tidak membalas celaan itu.Ia menjawab gunjingan wanita-wanita Mesir saat itu dengan mengadakan perjamuan makan. Sebelum jamuan dimulai, semua tamu wanita diberikan pisau satu per satu.Saat mereka memegang pisau untuk memulai perjamuan, Zulaikha meminta Yusuf untuk menampakkan diri di hadapan para tamu. Dan apa yang terjadi? Para tamu wanita mendadak takjubdan terpesona, mereka mengagumi keindahan Yusuf hingga tanpa disadari mereka memotong jari tangan mereka sendiri.

Zulaikha tidak ambil pusing dengan celaan wanita-wanita Mesir itu.Ia justru mengajak mereka untuk merasakan langsung apa yang dirasakannya. Zulaikha ingin memberikan kesempatan kepada wanita-wanita Mesir itu untuk naik banding pada pengalaman mereka dengan melihat Yusuf. Hal itu dilakukannya agar mereka dapat memahami apa yang dia rasakan dan lakukan selama ini. Jika pada pandangan pertama saja wanita-wanita Mesir itu sampai melukai tangannya sendiri, apatah

${ }^{4}$ Dadang Darmawan, "Kajian Hermeneutika Terhadap Fenomena dan Teks Agama",6-7. Mengenai hal ini Dadang merujuk kepada Sumaryono, Hermeneutik: Sebuah Metode Filsafat, 35-36; Palmer, Hermeneutics Interpretation Theory in Schleiermacher, Dilthey, Heidegger and Gadamer, 8497; Lawrence K.Schmidt,Understanding Hermeneutics, (Durham: Acumen Publishing Limited, 2010), 10-28; F.R Ankersmit,Refleksi tentang Sejarah: Pendapat-pendapat Modern tentang Filsafat Sejarah, (Jakarta, Gramedia, 1987), 156-157. 
lagi jika mereka bertemu Yusuf setiap hari seperti yang dirasakannya (Zulaikha). Allah berfirman:

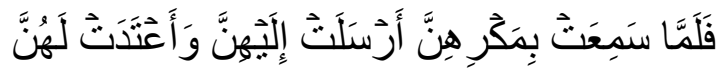

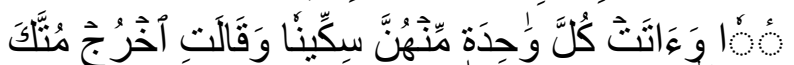

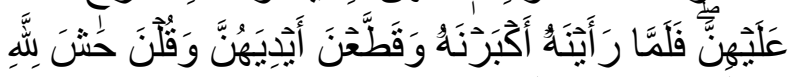

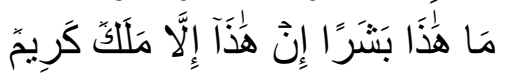

Maka tatkala wanita itu (Zulaikha) mendengar cercaan mereka, diundangnyalah wanita-wanita itu dan disediakannya bagi mereka tempat duduk, dan diberikan kepada masing-masing mereka sebuah pisau (untuk memotong jamuan), kemudian dia berkata (kepada Yusuf): "Keluarlah (nampakkan dirimu) kepada mereka," maka tatkala wanitawannita itu melihatnya, mereka kagum kepada (keelokan rupa)nya, dan mereka melukai (jari) tangannya dan berkata: "Maha sempurna Allah, ini bukanlah manusia. sesungguhnya ini tidak lain hanyalah malaikat yang mulia". 5

\section{Hermeneutika Dilthey}

Hermeneutika Dilthey bertumpu pada tiga kata kunci, yaitu (1) erlebnis, (2) ausdruck, dan (3) verstehen.Erlebnis adalah akumulasi pengalaman hidup yang dialami dan membentuk jati diri seseorang. Erlebnis adalah pintalan masa lalu dan masa kini seseorang.'Dengan pengalamanku di masa lalu aku pahami kejadian hari ini, dengan pengalamanku hari ini aku tinjau kembali masa laluku'.Erlebnis seseorang akan terekspresikan ke luar berupa perkataan, tindakan atau karya, yang oleh Dilthey disebut ausdruck. Dengan mengetahui erlebnis ataupengalaman hidup seseorang, kita akan memahami ausdruck atau perkataan, tindakan karya orang itu. Saat kita sudah memahami, itulah yang disebut verstehen. ${ }^{6}$

${ }^{5} \mathrm{QS}$ : Yusuf[12]:31.

${ }^{6}$ Dadang Darmawan, "Kajian Hermeneutika Terhadap Fenomena dan Teks Agama", 9. Mengenai hal ini Dadang merujuk kepada Sumaryono, Hermeneutik: Sebuah Metode Filsafat,47-48; Palmer, Hermeneutics Interpretation Theory in Schleiermacher, Dilthey, Heidegger and Gadamer,98123; Lawrence K.Schmidt, Understanding
Teori hermeneutika Dilthey membagi proses memahami suatu fenomena atau karya manusia melalui tiga tahap. Pertama, meneliti pengalaman hidup seseorang yang membentuk jatinya (erlebnis).Kedua, hasil penelitian itu digunakan untuk melihat fenomena atau karya orang itu.Ketiga mencoba memahami mengapa seseorang mengatakan sesuatu, melakukan suatu, atau mengapa sebuah teks ada, atau mengapa suatu karya lahir. ${ }^{7}$

Ketika Yusuf menceritakan mimpinya kepada ayahnya, ia justru diingatkan oleh ayahnya untuk tidak meceritakan mimpi itu kepada saudara-saudaranya. Mengapa Ya'qub berbuat demikian?Jika dibaca menggunakan hermeneutika Dilthey, nampaknyaYa'qub sangat mengenal karakter maupun tabiat anakanaknya yang kurang baik, atau bisa saja Ya'qub sudah membaca gelagat kecemburuan anak-anaknya kepada Yusuf. Sehingga jika Yusuf sampai bercerita kepada saudarasaudaranya dikhawatirkan mereka akan semakin cemburu kepada Yusuf, sehingga keselamatan yusuf akan semakin terancam. Karena itulah Ya'qub melarang Yusuf bercerita tentang mimpinya agar tidak terjadi hal-hal yang tidak diinginkan.Allah berfirman:

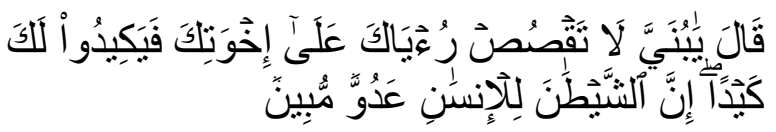

Ayahnya berkata: "Hai anakku, janganlah kamu ceritakan mimpimu itu kepada saudarasaudaramu, maka mereka membuat makar (untuk membinasakan)mu... ${ }^{8}$

Demikian pula ketika Yusuf akan diajak bermain jauh oleh saudara-saudaranya. Ya'qub menangkap gelagat yang kurang baik dalam ajakan itu, bukankah ia sangat mengkhawatrikan keselamatan Yusuf,

\footnotetext{
Hermeneutics,29-48; F.R Ankersmit,Refleksi tentang Sejarah: Pendapat-pendapat Modern tentang Filsafat Sejarah, 160-163.

${ }^{7}$ Dadang Darmawan, Dadang Darmawan, "Kajian Hermeneutika Terhadap Fenomena dan Teks Agama", 10.

${ }^{8}$ QS:Yusuf[12]:5.
} 
sehingga ia tidak mengizinkannya. Namun setelah ada itikad baik dari anak-anaknya itu akhirnya ia mengizinkannya. Disebutkan dalam Alquran:

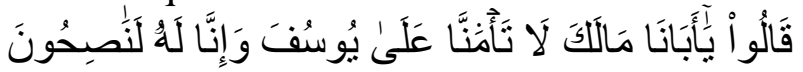

Mereka berkata: "Wahai ayah kami, apa sebabnya kamu tidak mempercayai kami terhadap Yusuf, padahal sesungguhnya kami adalah orang-orang yang menginginkan kebaikan baginya". 9

\section{Hermeneutika Gadamer}

Menurut Gadamer hermeneutika bukanlah metode untuk memahami, karena tidak ada cara yang baku untuk memahami. Kita hidup di dunia penuh arti.Sejak bangun tidur, kita sudah dihadapkan pada berbagai fenomena yang harus kita pahami.Memahami telah menjadi fitrah dan naluri manusia.Memahami adalah bagian dari eksistensi manusia itu sendiri. Kemampuan memahami itu pula yang akan membuat manusia mampu bertahan hidup di dunia ini. Memahami adalah bagian dari jati diri manusia.Maka bagi Gadamer, hermenetika itu lebih bersifat ontologis daripada metodologis.

Gagasan untuk membawa hermeneutika dari ranah epistemologi ke ranah ontologi membawa konsekuensi fundamental, bahwa kebenaran dari suatu pemahaman tidak ditentukan oleh bagaimana cara seseorang memahami, atau bagaimana hasil pemahamannya, melainkan dari respons yang ia terima karena pemahamannya itu. Setiap pemahaman membawa konsekuensi bagi orang yang memahaminya. Ketika manusia salah memahami maka besar kemungkinan ia akan menuai akibat yang sangat merugikan. ${ }^{10}$

${ }^{9}$ QS:Yusuf[12]:11.

${ }^{10}$ Dadang Darmawan, "Kajian Hermeneutika Terhadap Fenomena dan Teks Agama", 12. Mengenai hal ini Dadang merujuk kepada Sumaryono, Hermeneutik: Sebuah Metode Filsafat,71-80; Palmer, Hermeneutics Interpretation Theory in Schleiermacher, Dilthey, Heidegger and Gadamer,162-222; Lawrence K.Schmidt, Understanding Hermeneutics,95-132; F.R Ankersmit, Refleksi tentang Sejarah: Pendapat-pendapat Modern tentang Filsafat Sejarah, 164-166.
Hal ini sangat jelas terlihat pada perasaan hati Zulaikha kepada Yusuf. Bagi Zulaikha, Yusuf terlalu mengagumkan bagi dirinya, dariparas wajah, perilaku, maupun kharismanya, sampai-sampai ia tidak kuasa membendung perasaannya kepada Yusuf, sekalipunYusuf hanya seorang pembantu istana, tidak berpangkat dan tidak punya kekayaan. Baginya, rasa cinta itu nyata adanya, dan mungkin hanya dia yang bisa merasakannya, sekalipun wanita-wanita Mesir mencela dan mencerca perasaannya itu.Disebutkan dalam Alquran:

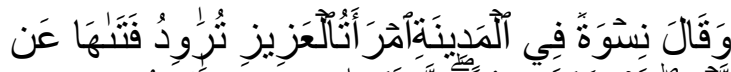

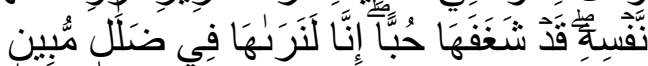

Dan wanita-wanita di kota berkta; ("Isteri al-Aziz) menggoda bujangnya untuk menundukkan dirinya (kepadanya), sesungguhnya cintanya kepada bujangnya itu adalah sangat mendalam. Sesungguhnya kami memandangnya dalam kesesatan yang nyata. $^{11}$

Hal serupa juga dialami oleh Ya'qub. Cinta kasihnya sebagai seorang ayah kepada Yusuf telah membuatnya larut dalam kesedihan yang mendalam, sehingga ia kehilangan penglihatannya karena terlalu banyak menangis. Hal itu berlangsungbeberapa tahun, hingga akhirnya aroma baju Yusuf yang dibawa saudara-saudaranya tercium dari jarak yang masih jauh.Begitu dalamnya rasa itu.Bagi Ya'qub kasih sayangnya kepada Yusuf begitu besar dan itu nyata baginya, sekalipun orang di sekitarnya menuduhnya lemah akal. Disebutkan dalam Alquran:

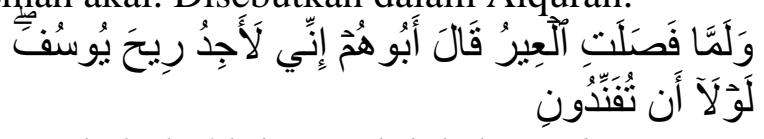

Tatkala kafilah itu telah keluar (dari negeri Mesir) berkata ayah mereka; "sesungguhnya aku mencium bau Yusuf, sekiranya kamu tidak menuduhku lemah akal (tentu kamu membenarkan aku).,"12

\footnotetext{
${ }^{11}$ QS:Yusuf[12]:30.

${ }^{12}$ QS:Yusuf[12]:94.
} 


\section{Hermeneutika Habermas}

Hermeneutika menurut Habermas adalah proses memahami melalui dialektika. Baginya kebenaran akan didapatkan melalui proses komunikasi yang aktif, bukan satu arah. Habermas membuka pintu yang luas dalam menemukan kebenaran dari sesuatu melalui proses bertanya, karena dengan bertanya maka kebenaran akan semakin mudah untuk diungkap.

Salah satu gagasan yang paling dikenal dari Habermas adalah 4 konsep tindakan/komunikasi, yaitu tindakan bertujuan (teleologis), tindakan normatif (mengikuti sistem), tindakan dramatugik (kepura-puraan) tindakan komunikatif (tindakan bertujuan dengan persetujuan)

Menurut habermas, komunikasi/tindakan komunikatif adalah tindakan yang paling ideal untuk membentuk masyarakat yang merdeka, independen, dan bebas dalam menentukan tujuan hidupnya sendiri. Masyarakat harus melakukan komunikasi-komunikasi baik verbal maupun non-verbal (communication action) agar dicapai apa yang disebutnya sebagai kesadaran kolektif, yaitu dalam bentuk kesepakatan atau konsensus. Maka di sinilah harus ada ruang publik (public space) yang bebas bagi semua pihak untuk berkomunikasi dengan baik untuk memecahkan berbagai masalah yang dihadapinya, sehingga dengan demikian masyarakat memiliki kesadaran yang benar dan terhindar dari pola komunikasi yang dimonopoli oleh pihak yang kuat dan berkuasa. $^{13}$

Menarik untuk mencermati dialog raja Mesir dengan para penasehatnya untuk mencari takwil atas mimpi yang dialaminya. Disebutkan dalam Alquran:

\footnotetext{
${ }^{13}$ Dadang Darmawan, "Kajian Hermeneutika Terhadap Fenomena dan Teks Agama", 16. Mengenai hal ini Dadang merujuk kepada Sumaryono, Hermeneutik: Sebuah Metode Filsafat,90-96.
}

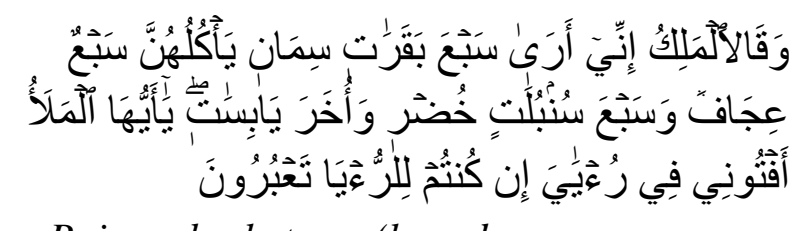

Raja berkata (kepada orang-orang terkemuka dari kaumnya): "Sesungguhnya aku bermimpi melihat tujuh ekor sapi betina yang gemuk-gemuk dimakan oleh tujuh ekor sapi betina yang kurus-kurus dan tujuh blir (gandum) yang hijau dan tujuh bulir lainnya yang kering." Hai orang-orang yang terkemuka: "Terangkanlah kepadaku tentang ta'bir mimpiku itu jika kamu dapat mena'birkan mimpi. ${ }^{14}$

Jika ditinjau dari persfektif hermeneutika Habermas, upaya dialogis raja Mesir dengan para pemuka kaumnya untuk mencari arti mimpinya adalah tindakan yang penuh dengan nilai komunikatif.Raja membuka ruang yang luas dalam mencari kebenaran dari mimpinya, sehingga terjadi pertukaran informasi antar raja dengan pemuka kaum, atau siapa saja yang mendengarkannya.Raja dengan kekuasaannya tidak sewenang-wenang dalam menentukan arti mimpinya.

Tindakan komunikatif raja ini pada akhirnya membuahkan hasil.Mimpi raja dapat ditakwilkan oleh Yusuf setelah seorang pelayan kerajaan mengadukan mimpi itu kepadanya. Paling tidak, tindakan komunikatif akan memperbanyak sudut pandang atau sumber informasi untuk mendapatkan kebenaran yang dimaksud. Walhasil, raja dan bangsa Mesir terhindar dari bencana yang lebih buruk akibat peceklik tujuh tahun lamanya.

Berbeda dengan tindakan komunikatif raja mesir, saudara-saudara Yusuf justru melakukan tindakan-tindakan yang dalam pandangan hermenenutika Habermas dikategorikan dramatugik. Ketika mereka berhasil menyingkirkan Yusuf dari rumah,

\footnotetext{
${ }^{14}$ QS:Yusuf[12]:43.
} 
mereka pulang ke rumah ayahnya sambil purapura menangis dengan membawa pakaian Yusuf yang tercabik dan berlumuran darah seraya menyatakan bahwa Yusuf telah mati dimakan serigala saat mereka pergi berkejarkejaran. Disebutkan dalam Alquran:

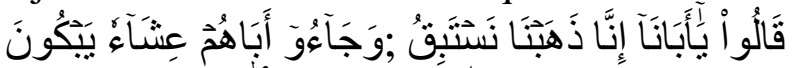

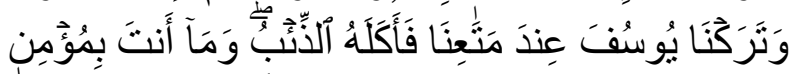

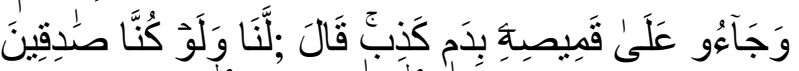

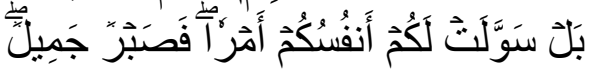

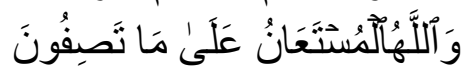

Kemudian mereka datang kepada mereka di sore hari sambil menangis.Mereka berkata;

"Wahai ayah kami, sesungguhnya kami pergi berlomba-lomba dan kami tinggalkan Yusuf di dekat barang-barang kami, lalu dia dimakan serigala; dan kamu sekali-kali tidak akan percaya kepada kami, sekalipun kami adalah orang-orang yang benar. Mereka datang dengan membawa baju gamsinya (yangberlumuran) dengan darah palsu.... ${ }^{15}$

Dilihat dari motifnya, tindakan ini sudah negatif. Sedari awal mereka telah mengarang cerita dan mendramatisir kejadian itu sedemikian rupa agar ayah mereka mempercayai cerita tersebut, karena mereka tahu ayahnya tidak akan semudah itu mempercayai cerita mereka. Mereka menutup serapat mungkin ruang dialog maupun komunikasi dialektis itu karena secara sepihak mereka telah menentukan sendiri ujung dari pembicaraan tersebut sesuai dengan keinginan mereka. Dalam persfektif hermeneutika Habermas, tindakan semacam ini bukanlah tindakan yang ideal untuk mencari kebenaran bersama.

\section{Hermeneutika Ricoeur}

Pendekatan hermeneutika Ricoeur lebih menekankan pada makna objektif yang dikandung oleh suatu teks, iatidak lagi terlalu disibukkan untuk mengungkap maksud pengarang maupun kondisi ketika teks itu di

\footnotetext{
${ }^{15}$ QS:Yusuf[12]:16-18.
}

buat. Karenanya tugas hermeneutika hanyalah dua, yakni mencari "dinamika" yang terdapat dalam teks, dan mencari "kekuatan" yang dimiliki teks itu agar kekuatan itu dapat muncul ke permukaan.

Pada dasarnya, Ricoeur berpendapat bahwa teks adalah sesuatu yang universal, ia tidak dibatasi oleh waktu dan objek tertentu. Pemahaman terdahulu terhadap suatu teks boleh jadi berbeda dengan masa kini, atau bisa juga pemahaman teks di tempat tertentu berbeda dengan pemahaman di tempat lain, maka suatu teks berpotensi memiliki pluralitas makna.Hermeneutika bertujuan untuk mempersempit potensi prularitas makna itu dengan mengungkap makna sebenarnya dari sebuah teks.Hal tersebut memungkinkan suatu teks menemukan pemahaman baru yang relevan menembus ruang dan waktu. Teks yang disampaikan di masa lalu namun memiliki dinamika yang kuat tidak akan kehilangan eksistensinya dan akan selalu menemukan aktualisasinya dengan realitas zaman. $^{16}$

Berkaitan dengan hermeneutika Ricoeur, patut kiranya menggarisbawahi pesan Ya'qub kepada anak-anaknya saat mereka diminta mencari jejak Yusuf dan saudaranya. Disebutkan dalam Alquran:

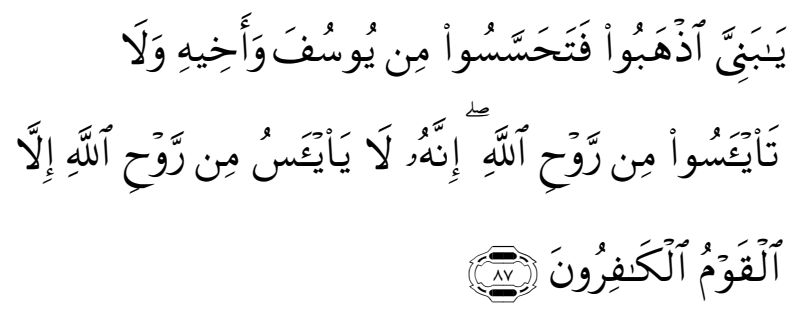

Hai anak-anakku, pergilah kamu, maka carilah berita tentang Yusuf dan saudarasaudaranya dan jangan kamu berputus asa dari rahmat Allah.Sesungguhnya tiada berputus asa dari rahmat Allah, melainkan kaum yang kafir. ${ }^{17}$

\footnotetext{
${ }^{16}$ Dadang Darmawan, "Kajian Hermeneutika Terhadap Fenomena dan Teks Agama", 18-19. Mengenai hal ini Dadang merujuk kepada Sumaryono, Hermeneutik: Sebuah Metode Filsafat, 105-109.

${ }^{17}$ QS:Yusuf [12]:87.
} 
Dilihat dari konteksnya, redaksi ayatnya menunjukkan bahwa ini adalah pesan Ya'qub kepada anak-anaknya agar tidak menyerah dan berputus asa untuk mencari Yusuf dan adiknya.Sebuah nasehat yang dalam.Bagaimana tidak, Ya'qub meminta anak-anaknya untuk melakukan sesuatu yang aneh, menemukan Yusuf padahal dahulu Yusuf dikabarkan telah meninggal oleh anakanaknya sendiri.Entah karena ketidakpercayaan Ya'qub kepada anak-anaknya atau memang Ya'qub meyakini betul bahwa Yusuf masih hidup.

Namun jika kita rekontekstualisasi, seperti yang digambarkan hermeneutika Ricoeur, maka pada dasarnya ayat ini akan selalu relevan diaplikasikan di manapun dan kapanpun. Ayat ini memiliki dinamika teks yang kuat, menembus ruang dan waktu.Setiap katanya seakan memiliki kekuatan yang luar biasa dan mampu mempengaruhi setiap jiwa yang membacanya.

Bukankah setiap orang, di masa lalu, sekarang dan masa depan pernah menghadapi sesuatu atau kondisi sulit dalam hidupnya? Kesulitan itu tidak jarang membuat mereka berhenti melangkah, menyerah, bahkan putus asa. Ya'qub pernah mengalami hal tersebut, setelah ia kehilangan Yusuf, ia juga harus menerima kenyataan kehilangan putra bungsunya, Bunyamin. Bahkan mereka tengah berada dalam suasana paceklik yang mencekik mereka sekeluarga. Namun, Ya'qub terus bertahan, ia sekuat tenaga tetap menyalakan api harapan dalam dadanya untuk dapat bertemu Yusuf dan Bunyamin, serta mampu mengatasi kesulitan di masa paceklik itu

Dalam kondisi yang serupa, kita juga seharusnya melakukan hal yang sama. Kita harus tetapberusaha memelihara dan memperjuangkan harapan yang baik dalam hidup kita, terus melangkah, bahkan di saat segalanya terasa sulit dan tidak mungkin.Berputus asa bukanlah pilihan yang benar.Hanya dengan terus melangkah seseorang akan selalu menjadi lebih kuat, sekalipun awalnya mungkin terasa berat.

\section{Hermeneutika Derrida}

Derrida dikenal karena gagasan dekonstuksinya. Dekonstruksi adalah gabungan dari proses deskripsi (penggambaran) dan transformsi (perubahan). Dekonstruksi pada dasarnya adalahcara berpikir untuk menggoyang apa yang sudah dianggap mapan. Tujuan utamanya adalah ingin mengubah interpretasi mapan dari suatu teks berdasarkan apa yang dimiliki oleh teks itu sendiri. Celah kontradiksi itu bisa ditemukan dari kalimat kecil, sisipan kata, atau kondisi riil suatu tek atau kejadian.

Derrida memandang bahwa setiap teks memiliki potensi untuk mendekonstrusi dirinya sendiri, sehingga teks selalu dapat dibaca dan difahami dengan cara yang berbeda. Oleh karenanya tidak ada tafsir yang otoritatif.Oleh karenanyaklaim kebenaran bersifat ditangguhkan (difference), apa yang diketahui hanyalah jejak-jejak (trace) dari kebenaran, dan setiap teks memiliki potensi untuk terus menerus dimaknai di dalam konteks yang berbeda-beda (iterabilitas). Oleh karena itu melalui hermeneutika Derrida pemahaman yang mapan mengenai suatu hadits dapat saja dikritisi dengan mengajukan argumen yang kuat dan dapat dipertanggungjawabkan. ${ }^{18}$

Apa yang dikemukakan Derrida mengenai kritik teks maupun teori dekonstruksinya mengingatkan kita pada sebuah episode dalam perjalanan hidup nabi Yusuf. Hal ini dapat ditemui pada kasus Zulaikha yang telah menuduh Yusuf hendak berbuat jahat kepadanya. Namun Yusuf membantahnya. Untuk mencari kebenarannya, maka seorang dari keluarga Zulaikha memberikan argumentasinya. Disebutkan dalam Alquran:

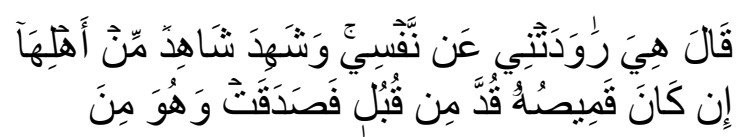

\footnotetext{
${ }^{18}$ Dadang Darmawan, "Kajian Hermeneutika Terhadap Fenomena dan Teks Agama”, 21. Mengenai hal ini Dadang merujuk kepada Sumaryono, Hermeneutik: Sebuah Metode Filsafat, 120-124.
} 


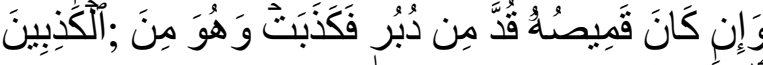
ألصَّدِقينَ

....dan seorang saksi dari keluarga wanita itu memberikan kesaksiannya; "Jika baju gamisnya koyak di muka, maka wanita itu benar, dan Yusuf termasuk orang-orang yang dusta.Dan jika baju gamsinya koyak di belakang, maka wanita itulah yang dusta, dan Yusuf termasuk orang-orang yang benar. ${ }^{19}$

Celah dekonstruksi terhadap tuduhan Zulaikha itu ternyata ada pada sobekan baju Yusuf.Sepertinya sobekan baju itu bukanlah hal yang penting, sesuatu yang mungkin sepele, tetapi ternyata itulah yang mengungkapkan kejadian sebenarnya.Ketika gamis Yusuf diperiksa dan didapati sobekan itu ada di bagian belakangnya, menjadi teranglah bahwa Yusuf tidak bersalah.

\section{Hermeneutika Heiddeger}

Hermeneutika Heidegger dikenal dengan konsep fenomenologinya.Sekalipun ia bukan penggagasnya, namun kajian ide hermeneutikanya banyak dipengaruhi olehide fenomenologi. Menurutnya, suatuteks atau fenomena tidak hanya dilihat dari apa yang nampak saja, tetapi ada bagian yang tidak terlihat yang boleh jadi itulah hakikat sesuatu tersebut. Oleh karenanya untuk memahami suatu teks atau fenomena seseorang harus bisa melihat bagian yang masih tersembunyi dari teks atau fenomena tersebut. ${ }^{20}$

Dalam kisah Yusuf, rangkaian peristiwa yang dialaminya saling berkaitan antara satu dengan yang lain, ada suka dan duka.Sepintas jika kita melihat hanya dari apa yang nampak kasat mata, maka kita akan mengatakan bahwa Yusuf bernasib buruk, hidupnya penuh derita, disisihkan oleh saudara-saudaranya, dijual kepada Kerajaan Mesir, dituduh hendak mendzalimi istri pejabat Negara, hingga masuknya ia ke penjara, maka yang tergambar adalah kepedihan, kesedihan dan kemalangan.

Tetapi jika kita berdiri lebih tinggi, berfikir lebih dalam maka kita akanmelihat bahwa rangkaian peristiwa-peristiwa yang buruk yang menimpa Yusuf adalah sebuah ujian dan batu loncatan, Yusuf mampu menghadapi dan melewati pengalaman-pengalaman pahit itu dengan sikap yang benar. Sehingga semuanya ibarat anak tangga yang mengantarkan Yusuf pada ta'wil mimpinya.Ada rencana kebaikan di balik peristiwa menyedihkan.

Pada akhirnya puing-puing kepedihan itulah yang membangun sejarah Yusuf hingga mencapai derajat tinggi baik sebagai abdi negara, maupun sebagai hamba sekaligus utusan Allah.Ia mencapai puncak karir finansial, sosial, maupun spiritualnya setelah melewati beragam ujian, menelan pil pahit yang menempa jiwa dan kesadarannya. Disebutkan dalam Alquran:

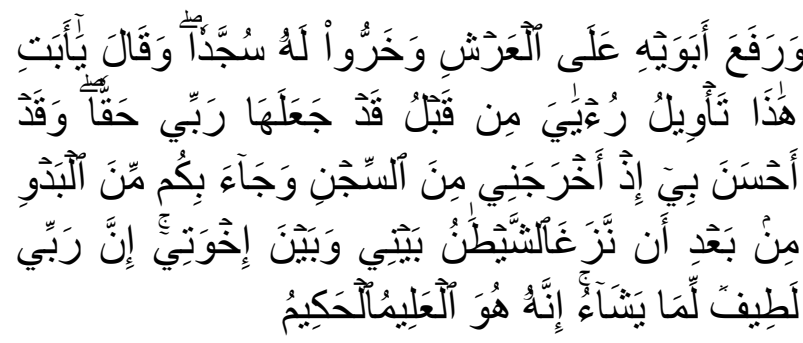

......Dan berkata Yusuf: "Wahai ayahku inilah tabir mimpiku yang dahulu itu; sesungguhnya Tuhanku telah menjadikannya suatu kenyataan. Dan sesungguhnya Tuhanku telah berbuat baik kepadaku, ketika Dia membebaskan aku dari rumah penjara dan ketika membawa kamu dari dusun padang pasir, setelah syaitan merusakkan (hubungan) antara aku dan saudara-saudaraku. Sesungguhnya Tuhanku Maha Lembut terhadap apa yang Dia kehendaki. Sesungguhnya Dialah Yang Maha Mengetahui lagi Maha Bijaksana. ${ }^{21}$

\footnotetext{
${ }^{19}$ QS:Yusuf[12]:26-27.

${ }^{20}$ Palmer, Hermeneutics Interpretation Theory in Schleiermacher, Dilthey, Heidegger and Gadamer, $127-$ 139.
}

${ }^{21}$ QS:Yusuf[12]:100. 
Hal serupa seringkali terjadi pada kehidupan kita. Bukankah dalam kehidupan ini kita sering terlalu terburu-buru menerka maksud dari suatu kejadian berdasarkan apa yang nampak oleh mata. Jika ditimpa kesenangan kita menganggapnya sebuah berkah, tetapi ketika ditimpa kemalangan kita menganggap itu sebuah nasib buruk.Padahal jika berkaca pada kisah Yusuf, boleh jadi kelelahan, kepedihan dan kemalangan yang mungkin kita alami saat ini ada kebaikan yang belum kita lihat, ada rencana Allah yang masih menjadi rahasia.

Dalam menjalani kehidupan ini, kita akan selalu dihadapkan pada fenomena-fenomena yang baik atau pun tidak, menyenangkan atau pun tidak. Seringkali fenomena itu mempengaruhi semangat dan hidup kita. Jika kita meyakini bahwa ada sesuatu di balik setiap fenomena maka kita akan terus menjaga harapan dan kewaspadaan.

Jika bertemu kebaikan dan kesenangan, jangan terlalu berbangga diri, karena boleh jadi ada keburukan yang menanti. Namun jika bertemu dengan kepayahan dan kepedihan, maka berbesar hatilah, tetaplah berharap karena boleh jadi di balik kepedihan itu ada ratusan anak tangga yang kelak akan mengantarkan kita pada mimpi-mimpi kita.

\section{SIMPULAN}

Alquran Surat Yusuf ditutup dengan suatu penegasan bahwa kisah yang diceritakan di dalamnya itu benar dan mengandung pelajaran bagi orang-orang yang intelek. Tulisan ini telah mencoba membeberkan model atau cara belajar yang unik dari kisah tersebut, yakni cara belajar ala hermeneutika. Dalam kisah itu kita dapat melihat cara manusia mengalami, memahami dan merespon berbagai persoalan serta akibat-akibat yang ditimbulkannya. Tentu saja setelah mempelajari kisah itu kita diharapkan dapat menjadi manusia yang lebih bijaksana. Bukankah itu tujuan kita mempelajari Alquran, dan bukankah itu pula tujuan kita mempelajari filsafat semacam hermeneutika ini, yaitu untuk menjadi manusia yang lebih bijaksana, yang dalam istilah Alquran disebut ulu al-bab. Wa Allahu 'alam.

\section{DAFTAR PUSTAKA}

Ankersmit, F.R. Refleksi tentang Sejarah: Pendapat-pendapat Modern tentang Filsafat Sejarah. Jakarta: Gramedia, 1987.

Bertens, Kees. Filsafat Barat Kontemporer Prancis.Jakarta: Gramedia, 2001. Filsafat Barat Kontemporer Inggris Jerman. Jakarta: Gramedia, 2002.

Bukhari, Muhammad bin Isma'il. Shahih alBukhari. CD Mawsu'ah al-Hadits alSyarif, Syirkah al-Baramij al-Islamiyyah al-Dawliyyah, 2000.

Ibn al-Hajar, Al-'Asqalani. Bulughal-Maram. Beirut, Dar al-Fikr, 1900

Ibn al-Hajjaj, Muslim. Shahih Muslim. CD Mawsu'ah al-Hadis al-Syarif, Syirkah alBaramij al-Islamiyah al-Dawliayh, 2000.

Powell, Jason. Jacques Derrida: A Biography. London: Continuum, 2006.

Palmer, Richard E..Hermeneutics Interpretation Theory in Schleiermacher, Dilthey, Heidegger and Gadameri. Northwestern University Press, 1969.

Rudolf A. Makkreed, "Wilhelm Dilthey", dalam Oppi, Nineteenth Century of Philosophy of Religion, The History of Western Philosophy of Religion Vol. 4, Newyork: Routledge, 2014.

Sumaryono, E., Hermeneutik, Sebuah Metode Filsafat, Yogyakarta: Kanisius, 1999.

Theodore Vial. "Friedrich Schleiermacher", dalam Oppi, Graham and N.N. Trakakis (editor), Nineteenth Century of Philosophy of Religion, The History of Western Philosophy of Religion Vol. 4, Newyork: Routledge, 2014. 